\title{
Usefulness of Endoscopic Transpapillary Tissue Sampling for Malignant Biliary Strictures and Predictive Factors of Diagnostic Accuracy
}

\author{
Hiroki Tanaka', Shimpei Matsusaki ${ }^{1}$, Youichirou Baba ${ }^{2}$, Yoshiaki Isono ${ }^{1}$, Tomohiro Sase ${ }^{1}$, Hiroshi Okano ${ }^{1}$, Tomonori Saito ${ }^{1}$, \\ Katsumi Mukai', Tetsuya Murata ${ }^{2}$ and Hiroki Taoka ${ }^{3}$ \\ Department of ${ }^{1}$ Gastroenterology, ${ }^{2}$ Pathology, ${ }^{3}$ Surgery, Suzuka General Hospital, Suzuka, Japan
}

Background/Aims: It is sometimes difficult to distinguish between malignant and benign biliary strictures using imaging studies alone, and pathological diagnosis is necessary. The aim of this study was to determine the usefulness of endoscopic transpapillary tissue sampling and factors predictive of diagnostic accuracy.

Methods: From April 2008 to December 2014, 136 patients underwent endoscopic transpapillary tissue sampling for malignant biliary strictures. The cytological and histological findings were reported as negative, suspicious, or positive. Suspicious and positive findings were defined as pathologically positive.

Results: The sensitivity was $65.0 \%$ for forceps biopsy, $49.5 \%$ for brush cytology, $46.2 \%$ for bile aspiration cytology, and $21.9 \%$ for endoscopic nasobiliary drainage cytology. The combination of these procedures improved the sensitivity (72.8\%). Endoscopic transpapillary tissue sampling was more sensitive for lesions of biliary origin (91.4\%) than for extrabiliary lesions (66.3\%). In surgical cases, the sensitivity for tumors with an infiltrative growth pattern (53.3\%) was significantly lower than for a tumor with an expanding or intermediate growth pattern (87.5\%).

Conclusions: Combining procedures can improve diagnostic accuracy. It may be possible to predict the sensitivity of endoscopic transpapillary tissue sampling by evaluating the etiology and tumor growth pattern using preoperative imaging studies. Clin Endosc 2018;51:174-180

Key Words: Biliary tract neoplasms; Pancreatic neoplasms; Endoscopic retrograde cholangiography; Obstructive janudice

\section{INTRODUCTION}

It is sometimes difficult to distinguish between malignant and benign causes of biliary strictures such as immunoglobulin G4-associated sclerosing cholangitis, primary sclerosing cholangitis, and others. Therefore, obtaining a correct patho-

Received: May 22, 2017 Revised: July 14, 2017

Accepted: July 14, 2017

Correspondence: Hiroki Tanaka

Department of Gastroenterology, Suzuka General Hospital, 1275-53 Yamanohana, Yasuzuka, Suzuka 513-0818, Japan

Tel: +81-59-382-1311, Fax: +81-59-384-1033, E-mail: hiroki.tanaka@miekosei.or.jp ORCID: https://orcid.org/0000-0001-9448-2191

(cc) This is an Open Access article distributed under the terms of the Creative Commons Attribution Non-Commercial License (http://creativecommons.org/ licenses/by-nc/3.0) which permits unrestricted non-commercial use, distribution, and reproduction in any medium, provided the original work is properly cited. logical diagnosis is important. Most malignant biliary strictures are associated with obstructive jaundice, and endoscopic transpapillary tissue samples obtained by techniques such as forceps biopsy, brush cytology, and aspiration cytology are commonly performed during endoscopic biliary drainage (EBD). Several studies have revealed that combinations of these procedures improved the diagnostic accuracy for malignant biliary strictures. ${ }^{1-9}$ However, these procedures have limited sensitivity, and false-negative results are a matter of concern. The etiology of malignant biliary strictures, ${ }^{3-7,10,11}$ the location of the strictures, ${ }^{6,710}$ the pathological interpretation, ${ }^{4-6,10,12}$ and other factors reportedly contribute to the diagnosis. However, these factors are not fully understood. In this retrospective study, we evaluated the accuracy of diagnostic procedures and factors contributing to accuracy. 


\section{MATERIALS AND METHODS}

From April 2008 to December 2014, 136 patients with malignant biliary strictures underwent endoscopic transpapillary tissue sampling. A malignant biliary stricture was defined as the presence of obstructive jaundice due to a malignant tumor. Patients with biliary strictures caused by protruding-type ampullary cancer were excluded from the study. The protocol for endoscopic retrograde cholangiopancreatography (ERCP) and endoscopic transpapillary tissue sampling is described below. ERCP was performed using a side-viewing scope (JF260, TJF 260; Olympus, Tokyo, Japan). After deep cannulation and passage through a stricture, the bile juice above the stricture was aspirated with a catheter (MTW ERCP catheter; MTW Endoskopie, Wesel, Germany). This initially sampled bile juice was not used for aspiration cytology to avoid confusing tumor cells with inflammatory atypia. Cholangiography and endoscopic sphincterotomy were performed before tissue sampling. Endoscopic transpapillary tissue sampling was performed with a biopsy forceps (FB-46Q-1; Olympus), cytology brush (Brush Master V; Olympus, and RX Cytology Brush; Boston Scientific Japan, Tokyo, Japan). Forceps biopsy and brush cytology were performed in all patients except when the devices could not be passed through the stricture. Forceps biopsy preceded other procedures. Bile aspiration cytology was performed after forceps biopsy and/or brush cytology. After endoscopic transpapillary tissue sampling, endoscopic biliary stenting (EBS) or endoscopic nasobiliary drainage (ENBD) was performed at the operator's discretion. EBS was performed using a 7.0- or 8.5-Fr plastic stent (RX Biliary Stent; Boston Scientific Japan, and Quick Place V Biliary Stent; Olympus), and ENBD was performed using a 5- or 6-Fr tube (Quick Place V ENBD; Olympus). When ENBD was performed for EBD, bile juice obtained from the ENBD tube (but not from the placed bag) was evaluated for cytology (hereinafter referred to as ENBD cytology). ENBD cytology was performed once or twice per day (total of 1-3 times) and discontinued once the diagnosis was obtained. The cytological and histological findings were reported as negative, suspicious (for malignancy), or positive (for malignancy). Suspicious and positive findings were defined as pathologically positive. Pathologically negative cases were classified as insufficient material, inadequate material, normal bile duct epithelium, or inflammatory atypia/reactive change. Cases with negative results on initial endoscopic transpapillary tissue sampling either underwent re-examination with tissue sampling or other procedures such as endoscopic ultrasound-guided fine needle aspiration (EUS-FNA) at the operator's discretion. Some elderly patients having poor physical status underwent treatment without confirmation of the pathological diagnosis (with most of them receiving the best supportive care). The final diagnosis was made based on the pathological examination of resected specimens, imaging studies, and the patient's clinical course ( $\geq 1$ year). Statistical analysis was performed using Pearson's chi-squared test with Yate's continuity correction and Fisher's exact test, and a $p$-value of $<0.05$ was considered statistically significant.

\section{RESULTS}

\section{Baseline characteristics}

Table 1 shows the characteristics of the 136 patients enrolled in this study. The patients consisted of 79 men and 57 women (median age 74 years, range $45-94$ years). Of these, 55 had pancreatic cancer, 35 had extrahepatic cholangiocarcinoma (including perihilar cholangiocarcinoma), 25 had gallbladder cancer, 13 had intrahepatic cholangiocarcinoma, 5 had postoperative recurrences, and 3 had other cancers. Of the 136 patients with malignant biliary strictures, forceps biopsy, brush cytology, aspiration cytology, and ENBD cytol-

Table 1. Patients' Characteristics

\begin{tabular}{lc}
\hline Male: Female & $79: 57$ \\
\hline Age (yr) & Mean 74 (45-94) \\
\hline Final diagnosis & 55 \\
\hline Pancreatic cancer & 35 \\
\hline Extrahepatic cholangiocarcinoma & 25 \\
\hline Gallbladder cancer & 13 \\
\hline Intrahepatic cholangiocarcinoma & 1 \\
\hline Ampullary carcinoma & 5 \\
\hline Postoperative recurrences & 1 \\
\hline Pancreatic neuroendocrine carcinoma & 1 \\
\hline Metastatic cancer & \\
\hline
\end{tabular}

Table 2. Sensitivity of Endoscopic Transpapillary Tissue Sampling

\begin{tabular}{llc}
\hline (a) & Forceps biopsy & $80 / 123$ \\
& & $65.0 \%$ \\
(b) & Brush cytology & $55 / 111$ \\
& & $49.5 \%$ \\
(c) & Aspiration cytology & $36 / 78$ \\
& & $46.2 \%$ \\
(d) & ENBD cytology & $7 / 32$ \\
& & $21.9 \%$ \\
(e) & Combination of each procedure & $99 / 136$ \\
& & $72.8 \%$ \\
\hline
\end{tabular}

$P<0.05$ : (a) vs. (e), (b) vs. (e), (c) vs. (e), (d) vs. (e). ENBD, endoscopic nasobiliary drainage. 
ogy were performed in 123 (90.4\%), 111 (81.6\%), 78 (57.4\%), and $32(23.5 \%)$ patients, respectively.

\section{Outcomes of endoscopic transpapillary tissue sampling}

The sensitivity was $65.0 \%(80 / 123)$ for forceps biopsy, $49.5 \%$ (55/111) for brush cytology, 46.2\% (36/78) for bile aspiration cytology, and 21.9\% (7/32) for ENBD cytology (Table 2). The sensitivity of the combination of these procedures was $72.8 \%$ (99/136), which was significantly higher than that of each procedure alone. The sensitivity of forceps biopsy $(65.0 \%, 80 / 123)$ was the highest among all single procedures. Forceps biopsy was negative or not performed in 56 cases, and 50 of these patients underwent other procedures. The sensitivity in these cases was 20.0\% (9/45) for brush cytology, $34.3 \%$ (12/35) for bile aspiration cytology, and $11.1 \%(1 / 9)$ for ENBD cytology; 19 (38.0\%) patients were diagnosed by procedures without forceps biopsy. Among 37 patients in whom the initial endoscopic transpapillary tissue sampling was negative, 12 underwent re-examination with endoscopic

Table 3. Negative Results on Endoscopic Transpapillary Tissue Sampling

\begin{tabular}{|c|c|}
\hline & Methods for diagnosis \\
\hline Pancreatic cancer $(n=14)$ & $\begin{array}{l}\text { EUS-FNA } 4 \text {, liver biopsy } 1 \text {, } \\
\text { duodenal biopsy } 2 \\
\text { Imaging studies } 7\end{array}$ \\
\hline $\begin{array}{l}\text { Intrahepatic cholangiocarcinoma } \\
(n=4)\end{array}$ & $\begin{array}{l}\text { Liver biopsy } 2 \\
\text { Imaging studies } 2\end{array}$ \\
\hline Gallbladder cancer $(n=4)$ & Imaging studies 4 \\
\hline $\begin{array}{l}\text { Extrahepatic cholangiocarcinoma } \\
\quad(n=2)\end{array}$ & Imaging studies 2 \\
\hline Postoperative recurrences $(n=2)$ & $\begin{array}{l}\text { Liver biopsy } 1 \\
\text { Imaging studies } 1\end{array}$ \\
\hline $\begin{array}{l}\text { Pancreatic neuroendocrine } \\
\text { carcinoma }(n=1)\end{array}$ & EUS-FNA 1 \\
\hline Ampullary carcinoma $(n=1)$ & Duodenal biopsy 1 \\
\hline
\end{tabular}

EUS-FNA, endoscopic ultrasound-guided fine needle aspiration. transpapillary tissue sampling, and 9 had positive results. In total, 108 (79.4\%) patients were diagnosable with endoscopic transpapillary tissue sampling. Among 28 patients in whom endoscopic transpapillary tissue sampling was negative, 5 were diagnosed by EUS-FNA, 4 by liver biopsy, 3 by duodenal biopsy, and 16 by imaging studies (Table 3 ).

\section{Sensitivity by final diagnosis}

The sensitivity using a combination of procedures was $69.1 \%(38 / 55)$ for pancreatic cancer, $91.4 \%(32 / 35)$ for extrahepatic cholangiocarcinoma, $56.0 \%$ (14/25) for gallbladder cancer, and $61.5 \%(8 / 13)$ for intrahepatic cholangiocarcinoma (Table 4). Furthermore, malignant biliary strictures were classified as lesions of biliary origin (extrahepatic cholangiocarcinoma) or extrabiliary origin (pancreatic cancer, intrahepatic cholangiocarcinoma, gallbladder cancer, metastatic cancer, and postoperative recurrence). The sensitivity of endoscopic transpapillary tissue sampling for lesions of biliary origin $(91.4 \%, 32 / 35)$ was significantly higher than that for extrabiliary lesions $(66.3 \%, 67 / 101)$ (Table 5$)$. For each procedure, the sensitivity of forceps biopsy for lesions of biliary origin $(84.4 \%, 27 / 32)$ was significantly higher than that for extrabiliary lesions $(58.2 \%, 53 / 91)$, however, the sensitivity of brush cytology, aspiration cytology, and ENBD cytology was not significantly different between the biliary and extrabiliary lesions.

\section{Causes of false-negative results}

The causes of false-negative results on endoscopic transpapillary tissue sampling were classified as inadequate material, insufficient material, normal bile duct epithelium, or inflammatory atypia/reactive change (some duplication occurred). The most frequent cause of false-negative results on endoscopic transpapillary tissue sampling was the inability to obtain specimens from tumor tissues, regardless of the type of procedure used (Table 6).

Table 4. Sensitivity of Endoscopic Transpapillary Tissue Sampling by Final Diagnosis

\begin{tabular}{|c|c|c|c|c|c|}
\hline & $\begin{array}{c}\text { Forceps } \\
\text { biopsy }\end{array}$ & $\begin{array}{c}\text { Brush } \\
\text { cytology }\end{array}$ & $\begin{array}{c}\text { Aspiration } \\
\text { cytology }\end{array}$ & $\begin{array}{c}\text { ENBD } \\
\text { cytology }\end{array}$ & Total \\
\hline Pancreatic cancer $(n=55)$ & $\begin{array}{l}30 / 51 \\
58.8 \%\end{array}$ & $\begin{array}{l}23 / 47 \\
48.9 \%\end{array}$ & $\begin{array}{l}11 / 29 \\
37.9 \%\end{array}$ & $\begin{array}{c}1 / 9 \\
11.1 \%\end{array}$ & $\begin{array}{l}38 / 55 \\
69.1 \%\end{array}$ \\
\hline Extrahepatic cholangiocarcinoma $(n=35)$ & $\begin{array}{l}27 / 32 \\
84.4 \%\end{array}$ & $\begin{array}{l}16 / 27 \\
59.3 \%\end{array}$ & $\begin{array}{l}11 / 21 \\
52.4 \%\end{array}$ & $\begin{array}{c}2 / 10 \\
20.0 \%\end{array}$ & $\begin{array}{l}32 / 35 \\
91.4 \%\end{array}$ \\
\hline Gallbladder cancer $(n=25)$ & $\begin{array}{l}14 / 22 \\
63.6 \%\end{array}$ & $\begin{array}{l}11 / 22 \\
50.0 \%\end{array}$ & $\begin{array}{l}11 / 19 \\
57.9 \%\end{array}$ & $\begin{array}{c}3 / 9 \\
33.3 \%\end{array}$ & $\begin{array}{l}14 / 25 \\
56.0 \%\end{array}$ \\
\hline Intrahepatic cholangiocarcinoma $(n=13)$ & $\begin{array}{c}6 / 11 \\
54.5 \%\end{array}$ & $\begin{array}{c}3 / 11 \\
27.3 \%\end{array}$ & $\begin{array}{c}2 / 6 \\
33.3 \%\end{array}$ & $\begin{array}{c}1 / 3 \\
33.3 \%\end{array}$ & $\begin{array}{r}8 / 13 \\
61.5 \%\end{array}$ \\
\hline
\end{tabular}

ENBD, endoscopic nasobiliary drainage. 
Table 5. Sensitivity of Endoscopic Transpapillary Tissue Sampling by Final Diagnosis (Biliary-Origin Lesions vs. Extrabiliary-Origin Lesions)

\begin{tabular}{lccc}
\hline & $\begin{array}{c}\text { Biliary-origin lesions } \\
(\boldsymbol{n}=\mathbf{3 5})\end{array}$ & $\begin{array}{c}\text { Extrabiliary-origin lesions } \\
(\boldsymbol{n}=\mathbf{1 0 1})\end{array}$ & $\boldsymbol{p}$-value \\
\hline Forceps biopsy & $27 / 32$ & $53 / 91$ & 0.00923 \\
& $84.4 \%$ & $58.2 \%$ & 0.28 \\
Brush cytology & $16 / 27$ & $39 / 84$ & $46.4 \%$ \\
Aspiration cytology & $59.3 \%$ & $25 / 57$ & 0.61 \\
& $11 / 21$ & $43.9 \%$ & 1.00 \\
ENBD cytology & $52.4 \%$ & $5 / 22$ & $22.7 \%$ \\
\\
Total & $2 / 10$ & $67 / 101$ & 0.00378 \\
\end{tabular}

ENBD, endoscopic nasobiliary drainage.

Table 6. Causes of False-Negative Results

\begin{tabular}{|c|c|c|c|c|}
\hline & $\begin{array}{c}\text { Inadequate } \\
\text { material }\end{array}$ & $\begin{array}{c}\text { Insufficient } \\
\text { material }\end{array}$ & $\begin{array}{c}\text { Normal bile duct } \\
\text { epithelium }\end{array}$ & $\begin{array}{c}\text { Inflammatory atypia } \\
\text { Reactive change }\end{array}$ \\
\hline \multirow[t]{2}{*}{ Forceps biopsy } & $4 / 43$ & $5 / 43$ & $33 / 43$ & $3 / 43$ \\
\hline & $9.3 \%$ & $11.6 \%$ & $76.7 \%$ & $7.0 \%$ \\
\hline \multirow[t]{2}{*}{ Brush cytology } & $3 / 56$ & $4 / 56$ & $54 / 56$ & $0 / 56$ \\
\hline & $5.4 \%$ & $7.1 \%$ & $96.4 \%$ & $0 \%$ \\
\hline \multirow[t]{2}{*}{ Brush cytology } & $4 / 42$ & $1 / 42$ & $38 / 42$ & $0 / 42$ \\
\hline & $9.5 \%$ & $2.4 \%$ & $90.5 \%$ & $0 \%$ \\
\hline \multirow{2}{*}{ Aspiration cytology } & $1 / 25$ & $1 / 25$ & $23 / 25$ & $2 / 25$ \\
\hline & $4.0 \%$ & $4.0 \%$ & $92.0 \%$ & $8.0 \%$ \\
\hline
\end{tabular}

Table 7. Sensitivity by Cancer Infiltrative Pattern

\begin{tabular}{lccc}
\hline & Inf $\mathbf{a}(\boldsymbol{\alpha}), \mathbf{b}(\boldsymbol{\beta})$ & Inf $\mathbf{c}(\boldsymbol{\gamma})$ & $p$-value \\
\hline Biliary-origin lesions $(n=20)$ & $14 / 14$ & $4 / 6$ & 0.079 \\
& $100 \%$ & $66.7 \%$ & 0.369 \\
Extrabiliary-origin lesions $(n=19)$ & $7 / 10$ & $4 / 9$ & $44.4 \%$ \\
& $70.0 \%$ & $8 / 15$ & 0.027 \\
\hline
\end{tabular}

\section{Surgical cases}

Forty (29.4\%) of the 136 enrolled patients underwent surgery. Twenty patients had biliary lesions and 20 had extrabiliary lesions (11 had pancreatic cancer, 7 had gallbladder cancer, 1 had intrahepatic cholangiocarcinoma, and 1 had ampullary cancer). We analyzed the diagnostic sensitivity in these surgical cases according to the cancer infiltrative pattern and stromal volume, based on the Japanese Classification of Biliary Tract Carcinoma and Pancreatic Carcinoma. Two pathologists evaluated cancer infiltrative patterns and stromal volume based on the pathological findings of resected specimens. The cancer infiltrative pattern was classified as INF a ( $\alpha$ ) (expanding growth pattern), INF b ( $\beta$ ) (intermediate growth pattern), or INF c $(\gamma)$ (infiltrative growth pattern). The diagnostic sensitivity among all patients with INF a ( $\alpha)$ or INF b $(\beta)$ was $87.5 \%(21 / 24)$; among patients with biliary lesions, the sensitivity was $100.0 \%(14 / 14)$, and among those with extrabiliary lesions, the sensitivity was $70.0 \%(7 / 10)$ (Table 7). Conversely, the diagnostic sensitivity among all patients with INF c $(\gamma)$ was $53.3 \%(8 / 15)$, that among patients with biliary lesions was $66.7 \%(4 / 6)$, and that among patients with extrabiliary lesions was $44.4 \%$ (4/9). The sensitivity for inf $c(\gamma)(53.3 \%)$ tumors was significantly lower than that for INF a ( $\alpha)$ and INF b ( $\beta$ ) (87.5\%) tumors. The cancer stromal pattern was classified as med (scanty stroma), sci (abundant stroma), or int (intermediate type). The diagnostic sensitivity among all patients with med or int $(n=23)$ was $82.6 \%(19 / 23)$, that among patients with biliary lesions was $92.9 \%(13 / 14)$, and that among patients with extrabiliary lesions was $66.7 \%$ (6/9) (Table 8). Conversely, the diagnostic sensitivity among 
Table 8. Sensitivity by Cancer Stromal Volume

\begin{tabular}{lccc}
\hline & Med, int & Sci & $p$-value \\
\hline Biliary-origin lesions $(n=20)$ & $13 / 14$ & $4 / 6$ & 0.20 \\
& $92.9 \%$ & $66.7 \%$ & 0.65 \\
Extrabiliary-origin lesions $(n=19)$ & $6 / 9$ & $5 / 10$ & $50.0 \%$ \\
Total $(n=39)$ & $66.7 \%$ & $9 / 16$ & 0.15 \\
\end{tabular}

all patients with sci $(n=16)$ was $56.3 \%(9 / 16)$, that among patients with biliary lesions was $66.7 \%(4 / 6)$, and that among patients with extrabiliary lesions was $50.0 \%(5 / 10)$. The sensitivity for tumor with sci $(56.3 \%)$ was considerably lower than that for a tumor with med or int $(82.6 \%)$, although the difference was not statistically significant $(p=0.15)$.

\section{Complications}

Five $(3.7 \%)$ patients developed mild pancreatitis that improved with conservative treatment.

\section{DISCUSSION}

Malignant biliary strictures are caused by various diseases, including, pancreatic cancer, cholangiocarcinoma, gallbladder cancer, ampullary cancer, metastatic cancer, and others. It is sometimes difficult to distinguish between malignant and benign disease using imaging studies alone. In fact, $6.6 \%$ to $9.0 \%$ of patients who underwent surgery for suspected malignant biliary strictures were ultimately diagnosed with benign diseases based on the histological findings of the resected specimens. ${ }^{13,14}$ Therefore, preoperative pathological examination is important. Most malignant biliary strictures are associated with jaundice, and endoscopic transpapillary tissue sampling is commonly performed during EBD. The reported sensitivity of forceps biopsy, brush cytology, and aspiration cytology were $36.0 \%$ to $81.0 \%{ }^{3-9,11,15} 26.0 \%$ to $71.6 \%$, $9,11,12,15$ and $30.0 \%$ to $72.4 \%,{ }^{3,11,15,16}$ respectively, all of which have room for improvement. Several studies have revealed that a combination of these diagnostic methods improved the sensitivity. In the present study, the sensitivity of forceps biopsy (65.0\%) was highest among all single procedures, while a combination of procedures further improved the sensitivity (72.8\%). Sugiyama et al. reported that bile and brush cytology were not useful when forceps biopsy was negative, ${ }^{11}$ and Kurzawinski et al. reported that bile cytology was not useful when brush cytology was negative. ${ }^{17}$ However, in the present study, 8 (5.9\%) cases were positive on aspiration or ENBD cytology alone. Hence, a combination of methods, including, bile cytology was postulated to be more useful. Abdelghani et al. reported that the sensitivity of ENBD cytology was higher than that of percutaneous transhepatic biliary drainage cytology, and that bile cytology could be improved by scraping the stricture during ENBD. ${ }^{18}$ Furthermore, Rabinovitz et al. reported that the sensitivity of brush cytology could be improved by repeating brushing. ${ }^{19}$ These reports suggest that scraping the stricture may improve the sensitivity of bile cytology. In the present study, aspiration cytology was performed after forceps biopsy and/or brush cytology; this was partly the reason the combination with bile aspiration was useful.

False-negative results sometimes become a matter of concern during endoscopic transpapillary tissue sampling, and various factors that can influence the diagnostic accuracy include the histopathological interpretation, ${ }^{4-6,10,12}$ tumor characteristics, ${ }^{3-7,10,12}$ and procedural factors. ${ }^{4-7,10,12}$ Histopathological interpretations vary from one article to another, especially in cases with suspicious results, and close attention is needed when comparing the diagnostic accuracy among these reports. Furthermore, it is sometimes difficult to differentiate inflammatory atypia from malignancy. Thus, we should aspirate the bile juice above the stricture before performing aspiration cytology, especially in patients with combined cholangitis. With respect to tumor characteristics, the presence or absence of direct invasion of the bile duct, ${ }^{3-}$ $7,10,11$ the underlying etiology, ${ }^{3-7,10,11}$ and the location of the stricture ${ }^{6,710}$ were associated with the diagnostic accuracy. Extrabiliary lesions sometimes only compress the bile duct or invade submucosally instead of directly invading the bile duct epithelium. In the present study, the sensitivity of endoscopic transpapillary tissue sampling for biliary lesions (91.4\%) was significantly higher than for extrabiliary lesions (66.3\%), which is consistent with the findings in previous reports. Among single procedures, the sensitivity of forceps biopsy for biliary lesions (84.4\%) was significantly higher than for extrabiliary lesions (58.2\%); however, the sensitivity of brush cytology, aspiration cytology, and ENBD cytology was not significantly different between the biliary and extrabiliary lesions. This may suggest that it is important to obtain specimens from the entire stricture in extrabiliary lesions. Furthermore, flow cytometry, molecular genetic studies, and 
rapid on-site evaluation have been utilized in an attempt to improve diagnostic accuracy when only a small amount of specimen was available. ${ }^{1,2,5,7}$ However, some of the lesions in surgical patients in the present study showed no invasion to the bile duct epithelium. In our surgical cases, the sensitivity was significantly lower when the tumor showed an infiltrative growth pattern. Furthermore, the sensitivity was relatively lower, albeit not significantly, when the tumor showed a high cancer stromal volume. We think the probable explanation for these results was the presence of only a few malignant cells on the mucosal surface of the bile duct when the tumor showed an infiltrative growth pattern and high cancer stromal volume. Although better methods and devices are needed, we should recognize that certain cases that are difficult to diagnose by endoscopic transpapillary tissue sampling are present in definite proportions. We may be able to predict the sensitivity of endoscopic transpapillary tissue sampling by evaluating the etiology, tumor growth pattern, and cancer stromal volume based on preoperative imaging studies. EUS-FNA is reportedly useful when endoscopic transpapillary tissue sampling produces negative results, and may be superior, especially for extrabiliary lesions. ${ }^{9,20,21}$ We recommend performing EUS-FNA based on the preoperative imaging findings. Procedural factors that influence the diagnostic accuracy are mainly affected by the fact that endoscopic transpapillary tissue sampling is performed under fluoroscopy in two dimensions. ${ }^{4,67}$ In the present study, the most frequent cause of false-negative results was the inability to obtain specimens from the tumor tissues, regardless of the procedure and underlying etiology. Some recent reports have described SpyGlass (Boston Scientific Japan) cholangioscopy-guided biopsy. ${ }^{22-24}$ SpyGlass cholangioscopy makes it possible to perform biopsy under direct visualization, and is useful for both diagnosis of the etiology and determination of disease extent.

This study has certain limitations. It was a retrospective study involving a small number of surgical cases. A further study with a larger number of cases is required to clarify the usefulness of endoscopic transpapillary tissue sampling and the factors predictive of diagnostic accuracy.

In summary, the combination of forceps biopsy, brush cytology, aspiration cytology, and ENBD cytology can improve diagnostic accuracy for malignant biliary strictures. However, certain cases that are difficult to diagnose by endoscopic transpapillary tissue sampling are present in definite proportions. We should chose the most appropriate procedures based on the preoperative imaging findings.

\section{Conflicts of Interest}

The authors have no financial conflicts of interest.

\section{REFERENCES}

1. Navaneethan U, Njei B, Lourdusamy V, Konjeti R, Vargo JJ, Parsi MA. Comparative effectiveness of biliary brush cytology and intraductal biopsy for detection of malignant biliary strictures: a systematic review and meta-analysis. Gastrointest Endosc 2015;81:168-176.

2. de Bellis M, Sherman S, Fogel EL, et al. Tissue sampling at ERCP in suspected malignant biliary strictures (part 2). Gastrointest Endosc 2002;56:720-730.

3. Lee SJ, Lee YS, Lee MG, Lee SH, Shin E, Hwang JH. Triple-tissue sampling during endoscopic retrograde cholangiopancreatography increases the overall diagnostic sensitivity for cholangiocarcinoma. Gut Liver 2014;8:669-673.

4. Jailwala J, Fogel EL, Sherman S, et al. Triple-tissue sampling at ERCP in malignant biliary obstruction. Gastrointest Endosc 2000;51(4 Pt 1):383390.

5. Ponchon T, Gagnon P, Berger F, et al. Value of endobiliary brush cytology and biopsies for the diagnosis of malignant bile duct stenosis: results of a prospective study. Gastrointest Endosc 1995;42:565-572.

6. Pugliese V, Conio M, Nicolò G, Saccomanno S, Gatteschi B. Endoscopic retrograde forceps biopsy and brush cytology of biliary strictures: a prospective study. Gastrointest Endosc 1995;42:520-526.

7. Schoefl R, Haefner M, Wrba F, et al. Forceps biopsy and brush cytology during endoscopic retrograde cholangiopancreatography for the diagnosis of biliary stenoses. Scand J Gastroenterol 1997;32:363-368.

8. Kitajima Y, Ohara H, Nakazawa T, et al. Usefulness of transpapillary bile duct brushing cytology and forceps biopsy for improved diagnosis in patients with biliary strictures. J Gastroenterol Hepatol 2007;22:16151620 .

9. Rösch T, Hofrichter K, Frimberger E, et al. ERCP or EUS for tissue diagnosis of biliary strictures? A prospective comparative study. Gastrointest Endosc 2004;60:390-396.

10. De Bellis M, Sherman S, Fogel EL, et al. Tissue sampling at ERCP in suspected malignant biliary strictures (part 1). Gastrointest Endosc 2002;56:552-561.

11. Sugiyama M, Atomi Y, Wada N, Kuroda A, Muto T. Endoscopic transpapillary bile duct biopsy without sphincterotomy for diagnosing biliary strictures: a prospective comparative study with bile and brush cytology. Am J Gastroenterol 1996;91:465-467.

12. Logrono R, Kurtycz DF, Molina CP, Trivedi VA, Wong JY, Block KP. Analysis of false-negative diagnoses on endoscopic brush cytology of biliary and pancreatic duct strictures: the experience at 2 university hospitals. Arch Pathol Lab Med 2000;124:387-392.

13. Gerritsen A, Molenaar IQ, Bollen TL, et al. Preoperative characteristics of patients with presumed pancreatic cancer but ultimately benign disease: a multicenter series of 344 pancreatoduodenectomies. Ann Surg Oncol 2014;21:3999-4006

14. Abraham SC, Wilentz RE, Yeo CJ, et al. Pancreaticoduodenectomy (Whipple resections) in patients without malignancy: are they all 'chronic pancreatitis'? Am J Surg Pathol 2003;27:110-120.

15. Yagioka $\mathrm{H}$, Hirano $\mathrm{K}$, Isayama $\mathrm{H}$, et al. Clinical significance of bile cytology via an endoscopic nasobiliary drainage tube for pathological diagnosis of malignant biliary strictures. J Hepatobiliary Pancreat Sci 2011:18:211-215.

16. Uchida N, Kamada H, Ono M, et al. How many cytological examinations should be performed for the diagnosis of malignant biliary stricture via an endoscopic nasobiliary drainage tube? J Gastroenterol Hepatol 2008;23:1501-1504.

17. Kurzawinski T, Deery A, Dooley J, Dick R, Hobbs K, Davidson B. A prospective controlled study comparing brush and bile exfoliative cytology for diagnosing bile duct strictures. Gut 1992;33:1675-1677.

18. Abdelghani YA, Arisaka Y, Masuda D, et al. Bile aspiration cytology in diagnosis of bile duct carcinoma: factors associated with positive yields. J Hepatobiliary Pancreat Sci 2012;19:370-378. 
19. Rabinovitz M, Zajko AB, Hassanein T, et al. Diagnostic value of brush cytology in the diagnosis of bile duct carcinoma: a study in 65 patients with bile duct strictures. Hepatology 1990;12(4 Pt 1):747-752.

20. Weilert F, Bhat YM, Binmoeller KF, et al. EUS-FNA is superior to ERCP-based tissue sampling in suspected malignant biliary obstruction: results of a prospective, single-blind, comparative study. Gastrointest Endosc 2014;80:97-104.

21. Ohshima Y, Yasuda I, Kawakami H, et al. EUS-FNA for suspected malignant biliary strictures after negative endoscopic transpapillary brush cytology and forceps biopsy. J Gastroenterol 2011;46:921-928.
22. Kurihara T, Yasuda I, Isayama H, et al. Diagnostic and therapeutic single-operator cholangiopancreatoscopy in biliopancreatic diseases: prospective multicenter study in Japan. World J Gastroenterol 2016;22:18911901.

23. Woo YS, Lee JK, Oh SH, et al. Role of SpyGlass peroral cholangioscopy in the evaluation of indeterminate biliary lesions. Dig Dis Sci 2014;59:2565-2570

24. Tieu AH, Kumbhari V, Jakhete N, et al. Diagnostic and therapeutic utility of SpyGlass ${ }^{\circledast}$ peroral cholangioscopy in intraductal biliary disease: single-center, retrospective, cohort study. Dig Endosc 2015;27:479-485. 